\title{
Significance of Scaffolding and Peer Tutoring in the Light of Vygotsky's Theory of Zone of Proximal Development
}

\author{
Mehwish Haider and Aalyia Yasmin
}

\begin{abstract}
Peer tutoring helps more competent peers to scaffold learners within their Zone of Proximal Development to enhance their comprehension and cognitive development. Thus the present paper attempts to investigate the significance of scaffolding and peer tutoring to enhance the learners' understanding of English language particularly reading skills at school level. Experimental research design is used to conduct the present study. Data is computed, tabulated and analysed by using descriptive statistics of mean, median, SD, coefficient of variation, and inferential statistics of t-test. The outcome of present research highlights the significance of scaffolding and peer tutoring as the learners of the experimental group performed significantly better than the learners of the control group.
\end{abstract}

Index Terms-Peer tutoring, scaffolding, second language learning, zone of proximal development.

\section{INTRODUCTION}

Scaffolding and peer tutoring are important elements of cognitive learning theories. Cognitive theories of Piaget and Vygotsky ${ }^{1}$ have significantly influenced theory and practice of education all over the world. According to both the theorists, knowledge and comprehension is dynamically created by the developing person himself from the outward information instead of inactively absorbing it (Woolfolk, 2007) [1]. However, the theoretical move from Piaget to Vygotsky is from individual construction to social construction of information. For Vygotsky, the prime cause of cognitive development is internalization of societal activities with more knowledgeable others, including peers who are intellectually more competent (Matusov \& Hayes, 2000) [2].

Particular mental structures are important for the cognitive development which initially occur among child and more knowledgeable others at social level and after that they are internalized at the individual level. According to Vygotsky, the best way of teaching and learning is direct instruction in which a more knowledgeable peer helps learners in learning effectively by scaffolding them in their particular Zone of

Manuscript received on April 7, 2015; revised August 22, 2015.

The authors are with International Islamic University, Islamabad, Pakistan (e-mail: mahvish.haidar@gmail.com).

${ }^{1}$ Vygotsky's Socio Cultural Theory of human learning describes learning as a social process and the origination of human intelligence in society or culture. The major theme of Vygotsky's theoretical framework is that social interaction plays a fundamental role in the development of cognition.

Every function in the child's cultural development appears twice: first, on the social level, and later, on the individual level; first, between people (inter psychological) and then inside the child (intra psychological). This applies equally to voluntary attention, to logical memory, and to the formation of concepts. (Vygotsky, 1978, p. 57).
Proximal Development (Rizve, 2012) [3]. Zone of Proximal development is a distance between the actual level of students' development and the potential level of development. Actual level of development is where a learner can solve the task without taking any assistance while a learner needs assistance and guidance to solve a task in the potential level of development (Vygotsky, 1978) [4].

\section{THEORETICAL FRAMEWORK}

The present research is based on the Vygotsky's socio-cultural theory. ZPD is the key concept of socio-cultural theory. Scaffolding and peer tutoring are extensions of Vygotsky's notion of ZPD.

\section{A. Scaffolding and Peer Tutoring}

Scaffolding is assistance provided to the learners to understand the concept fully. The amount of scaffolding depends on the level of task difficulty. The term was introduced by Wood, Bruner and Ross and the concept was based upon Vygotsky's Zone of Proximal Development (Santrock, 2004) [5]. Scaffolding is usually provided by adults advanced in knowledge or teachers. In Scaffolding less competent learners are assisted by questioning, suggesting, displaying, narrating, boosting and recapping. ZPD is the area in which a learner can independently solve a task under assistance and guidance and that task cannot be accomplished independently by the learners. As a result of assistance, learners can independently solve the tasks that they were unable to solve previously. Hence, such kind of learning advances the child in cognitive development (Ormrod, 1998) [6].

Vygotsky (1987) [7] assumed that learning takes place within the children's zone of proximal development. This zone comprises of a series of activities too challenging for the child to achieve his own, however, likely to accomplish with the assistance of adults and more skilful peers. Children's' chances of learning increase when they are keenly involved in their learning. Peer tutoring is effective for learners as it enhances the learners' interest and polishes their academic skill (Shapiro and Levine, 1999) [8].

Peer tutoring is not only useful for academic development but also helpful for improvement in learners' attitude and motivation to learning. Vygotsky believes peers play a very significant role in the development of children. The healthy relationship between peers and children gives opportunity to children for a better kind of personal investigation and exploration. A child internalizes new patterns of thinking as a result of interaction with peers (Bukatko \& Daehler, 1995) [9]. 


\section{B. Context of the Study}

Recently a lot of research has been conducted on the effectiveness of scaffolding and peer tutoring in all over the world. However, there is still a need to investigate the usefulness of peer tutoring along with scaffolding in Pakistan. Though some efforts have been put to explore the cognitive development in child but peer tutoring is still ignored in Pakistan. It can play a vital role in Pakistan as it can be helpful to share the teachers' burden because of over-crowded classrooms.

\section{Objectives}

1) To enhance students' understanding of English language by incorporating scaffolding in teaching/learning situation.

2) To improve students' comprehension of English reading skills through peer tutoring.

\section{Hypothesis}

Scaffolding and Peer tutoring help to improve students' comprehension of reading skills.

\section{E. Null Hypothesis}

Scaffolding and Peer tutoring do not help to improve students' comprehension of reading skills.

\section{F. Delimitation}

The research is delimited to teaching of only reading skills which is one of the important skills of the English language learning. The level of students is grade 5 who are studying English language as a subject and for peer tutoring grade 7 is selected. It is a case study of International Islamic school system Rawalpindi campus, Pakistan.

\section{Methodology}

Experimental research design was used to conduct the present study.

\section{A. Sampling}

A sample of 50 students studying in class 5 was selected to conduct this study. Pre-test was conducted before the experiment to know about the level of the students. It was also used to equally distribute students in both the experimental and the control group. Pre-test was also conducted on the students of class 7. After the results of pre-test, 25 students were selected from class 7 to peer tutor the experimental group. 25 students of class 7 selected as peer tutors were more competent than the students of class 5 and were willing to tutor the young learners.

They were given training for 10 days to understand how they have to help out the learners of class 6 . Duration of experiment was 4 weeks. The researchers monitored the experimental group to ensure the effective peer tutoring.

Pre-test: Ten questions were included in the pre-test. Question statements were adapted from the text book of class 5 to facilitate learners to solve the test successfully. All questions carried equal marks.

Post-test: Ten questions were included in post-test as well. Question statements of pre and post-tests were similar. Questions were graded from simple to complex.
Proceeding: The experimental group worked in a pair as every participant of the experimental group was paired with the peer tutor of class 7. Learners interacted and discussed with the peers to internalize the concepts successfully. The researchers continuously monitored the experimental group for the successful implementation of peer tutoring in the class. On the other hand the control group was taught through conventional method of teaching where teacher is authoritative and student-teacher interaction is not welcomed.

\section{B. Research Tool}

Data collected through pre-test and post-test was analysed quantitatively through descriptive statistics of mean, median, $\mathrm{SD}$, coefficient of variation, and inferential statistics of t-test.

\section{ANALYSIS}

The performance of the experimental and the control group in pre-test and post-test was tabulated and analysed. A graph is presented below to explain the performance of the students in pre-test.

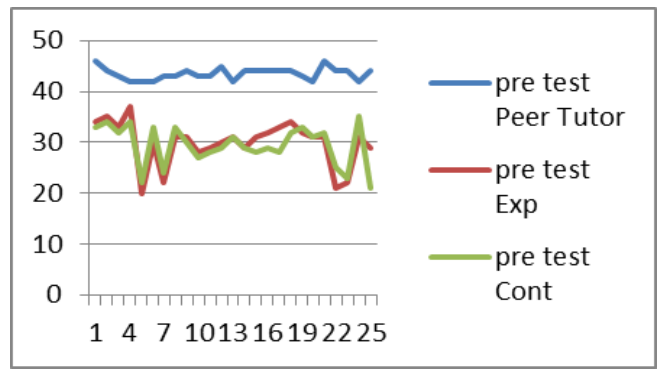

Fig. 1. Performance of students in pre-test.

The Fig. 1 represents the performance of the peer tutors, experimental group and control group in pre-test. The red line represents performance of experimental group in pre-test. The green line shows the performance of control group in pre-test. The blue line indicates the performance of peer tutor in pre-test. The red and green lines are overlapping at most of the points which reflects that both experimental and control performed almost equally in the pre-test. Whereas, the blue line illustrates that peer tutor group performed better than experimental and control group. It means that both experimental and control group are equal in competence and knowledge but peer tutor group have high competence than experimental and control group in reading skills.

TABLE I: COMPARISON OF CONTROL AND EXPERIMENT GROUP PRE-TEST

\begin{tabular}{|l|l|l|l|l|l|l|}
\hline \multicolumn{6}{|c|}{ Comparison of control and Experiment Group Pre test } \\
\hline & N & Mean & Median & SD & Q1 & Q3 \\
\hline Experiment & 25 & 30 & 31 & 4.4 & 29 & 32 \\
\hline Control & 25 & 30 & 30 & 4.2 & 28 & 33 \\
\hline
\end{tabular}

Note: $\mathrm{N}=$ number of students. $\mathrm{SD}=$ Standard Deviation, $\mathrm{Q} 1=$ First quartile, $\mathrm{Q} 3=$ Third quartile.

The Table I displays the comparison of pre-test scores of control and experimental group. Mean score of both the groups is similar that indicates the equal academic level of students. There is a slight difference in the median value of both the groups. Similarly SD, first quartile and the third quartile also have marginal differences that prove uniformity in groups on academic basis. 


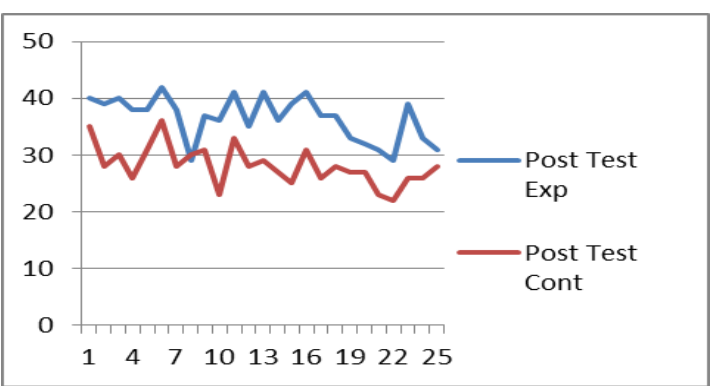

Fig. 2. Performance of students in post-test.

The Fig. 2 represents the performance of both the groups in post-test conducted after the experiment. The experimental group performed significantly better than the control group. The graph shows that maximum marks scored by the experimental group are 41 and the minimum score is 28 whereas the control group scored highest 36 marks and minimum 23 marks. The results go in the favour of the experimental group.

TABLE II: COMPARISON OF CONTROL AND EXPERIMENT GROUP POST-TEST

\begin{tabular}{|l|l|l|l|l|l|l|}
\hline \multicolumn{6}{|c|}{ Comparison of control and Experiment Group Post Test } \\
\hline & N & Mean & Median & SD & Q1 & Q3 \\
\hline Experiment & 25 & 36 & 37 & 3.89 & 33 & 39 \\
\hline Control & 25 & 29 & 28 & 5.7 & 25 & 34 \\
\hline
\end{tabular}

The Table II further elucidates the performances of students in the post-test. There is significant difference in the mean and median values of experimental and control group in the post- test performance which favour experimental group as more proficient and skilled learners. Values of first and third quartile also strengthen the improved performance of the experimental group.

\section{A. Levene's Test}

An independent t-test is applied on the scores of pre-test of experimental and control group to check their competence and knowledge. The following table shows the results.

TABLE III: T-TEST ANALYSIS OF PRE-TEST'S SCORES OF EXPERIMENTAL AND CONTROL GROUP

\begin{tabular}{|l|l|l|}
\hline \multicolumn{3}{|c|}{ T-Test: Two-Sample Assuming Unequal Variances } \\
\hline & Variable 1 & Variable 2 \\
\hline Mean & 29.88 & 29.44 \\
\hline Variance & 18.943333 & 15.756667 \\
\hline Observations & 25 & 25 \\
\hline $\begin{array}{l}\text { Hypothesized Mean } \\
\text { Difference }\end{array}$ & 0 & \\
\hline Df & 48 & \\
\hline$t$ Stat & 0.3734719 & \\
\hline$P(T<=t)$ one-tail & 0.3552209 & \\
\hline$t$ Critical one-tail & 1.6772242 & \\
\hline$P(T<=t)$ two-tail & 0.7104417 & \\
\hline$t$ Critical two-tail & 2.0106348 & \\
\hline
\end{tabular}

The Table III shows that the value of $t$ Critical two-tail is 2.010 which is greater than the value of $t$ Stat which is 0.373 . It means there is no significant difference in the performance of experimental and control groups. This analysis suggests that both experimental and control group have equal competence.
TABLE IV: T-TEST ANALYSIS OF POST-TEST'S SCORES OF EXPERIMENTAL AND CONTROL GROUP

\begin{tabular}{|l|l|l|}
\hline $\begin{array}{l}\text { t-Test: } \\
\text { Two-Sample } \\
\text { Assuming Equal } \\
\text { Variances }\end{array}$ & Variable 1 & Variable 2 \\
\hline Mean & & \\
\hline Variance & 36.48 & 27.76 \\
\hline Observations & 15.09333333 & 13.60666667 \\
\hline Pooled Variance & 14.35 & 25 \\
\hline $\begin{array}{l}\text { Hypothesized } \\
\text { Mean Difference }\end{array}$ & 0 & \\
\hline Df & 48 & \\
\hline$t$ Stat & 8.138521983 & \\
\hline$P(T<=t)$ one-tail & $6.80538 \mathrm{E}-11$ & \\
\hline$t$ Critical one-tail & 1.677224196 & \\
\hline$P(T<=t)$ two-tail & $1.36108 \mathrm{E}-10$ & \\
\hline$t$ Critical two-tail & 2.010634758 & \\
\hline
\end{tabular}

The Table IV displays the analysis of post-test' scores of experimental and control group. In the post-test value of $t$ state which is 8.138 is greater than the value of t Critical two-tail which is 2.01 . The results of the t-test illustrate that there is significant difference in the performance of experimental and control group. Experimental group performed better than the control group.

Thus, the analysis suggests that students of experimental group under scaffolding and peer tutoring improved their reading skills which proved the hypothesis of the study that Scaffolding and Peer tutoring help to improve students' reading skills. The results reject the null hypothesis that Scaffolding and Peer tutoring do not help to improve students' reading skills.

\section{FINDING AND DISCUSSION}

The findings of the research are as follow:

1) The scores of the pre- tests of experimental and control group were not significantly different.

2) The scores of post-test of experimental and control group were significantly different.

3) There is substantial difference between mean and median scores of post-test of experimental and control group which indicates that students of experimental group performed better than control group.

4) Experimental group was exposed to scaffolding which enhanced their learning skills.

5) Students of Experimental group were taught under peer tutoring which helped them to improve their reading skills.

6) Control group was not exposed to scaffolding and peer touring therefore there is no significant difference in their scores of pre and post-test.

7) The mean of pre-test's scores of experimental and control is same which establishes the belief that both groups are academically equal.

8) The mean and median values of post-test' scores of experimental and control groups are significantly different from each other which proved the hypothesis of the study.

The research was designed to investigate the effectiveness of scaffolding and peer tutoring on the performance of the 
learners of both the groups. The findings of the study reflect that peer tutoring and scaffolding play a vital role to enhance the learners' understanding of English language particularly reading skills. The outcome of present research is in line with the previously conducted studies such as Cheng \& Ku, 2009; Mehra \& Mondal, 2005; Topping, 2005 [10]-[12]. These studies also highlight the positive effects of peer tutoring on the academic development of students. On the whole the previous and present researches positively support the incorporation of scaffolding and peer tutoring in teaching.

In the light of findings the research objectives of the study are achieved as scaffolding and peer tutoring enhances students' understanding of English language and improved students' comprehension of English reading skills.

\section{CONCLUSION}

The research participants of experimental and control group were at same academic level in the beginning of the experiment. However, the learners educated through scaffolding and peer tutoring performed significantly better than the learners of the control group. Peer tutoring and scaffolding proved to be a significant method of instruction as compare to the conventional method of teaching. The learners taught through scaffolding and peer tutoring showed positive attitude towards learning. They also participated actively in learning process as compare to the control group. As a whole, the experimental group displayed a positively improved behaviour as a result of scaffolding and peer tutoring. As the research proved the hypothesis of the study therefore further researches should also be conducted on different levels of students. The same research can also be carried out to investigate effects of scaffolding and peer tutoring in learning different skills of English language.

\section{REFERENCES}

[1] A. Woolfolk, Educational Psychology, $10^{\text {th }}$ ed. Boston, MA: Pearson Educational, Inc., 2007.

[2] E. Matusov and R. Hayes, "Sociocultural critique of Piaget and Vygotsky," New Ideas in Psychology, pp. 215-239, 2000.

[3] R. Rizve, "The effect of peer tutoring on student achievement in the subject of English at secondary level in the light of Vygotsky's Theory," PhD dissertation, Foun Dation Univ., Islamabad, 2012.
[4] L. S. Vygotsky, Mind in Society: The Development of Higher Psychological Processes, M. Cole, V. John-Steniner, S. Scribner, and E. Souberman, Ed. Cambridge, Mass: Harvard University Press, 1978.

[5] J. W. Santrock, Educational Psychology, Boston: McGraw-Hill, 2004

[6] J. E. Ormrod, Educational Psychology, Developing Learners, $2^{\text {nd }}$ ed. Upper Saddle River, N.J.: Merrill.

[7] L. S. Vygotsky, "Thinking and speech," in the Collected Works of L. S. Vygotsky, vol. 1, R. W. Rieber and A. S. Carton, Eds. New York: Plenum Press, 1987, pp. 39-285.

[8] N. S. Shapiro and J. H. Levine, Creating Learning Communities, San Francisco: Jossey-Bass, 1999.

[9] D. Bukatko and M. W. Daehler, Child Development: A Thematic Approach, Boston: Hough ton Mifflin Company, 1995.

[10] Y. C. Cheng and H. Y. Ku. (2009). An investigation of the effects of reciprocal peer tutoring. Computers in Human Behavior. [Online]. pp. 40-49. Available http://www.sciencedirect.com/science/article/pii/S074756320800112 $\mathrm{X}$

[11] V. Mehra and H. R. Mondal. (2005). Effects of peer tutoring on learning outcomes of high school science students. Indian Educational Review. [Online]. 41(1). p. 41. Available: http://www.it.iitb.ac.in/ vijaya/ticet/dokuwiki/media/peer-tutoring.pd $\mathrm{f}$

[12] K. J. Topping. (2005). Trends in peer tutoring. Educational Psychology. [Online]. 25(6). pp. 631-645. Available: http://www.unibielefeld.de/Universitaet/Einrichtungen/SLK/peer_lear ning/pal/pdf/trends_in_peer_learning.pdf

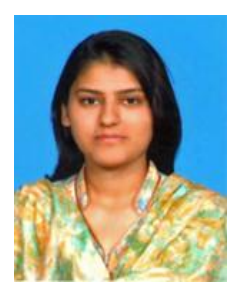

Mehwish Haider was born in Islamabad, Pakistan She is an MPhil scholar and currently serving in International Islamic University, Islamabad as a language teacher. Her area of specialization is linguistics. She completed her bachelor (Hons) and master's degrees in language and literature. She is teaching English language and literature at different levels since last four years. She has presented her research paper in the 2nd Kashmir International Linguistics Conference 2015, Pakistan. She has also organized many conferences and seminars in International Islamic University, Islamabad, Pakistan. She is also a member of International Economics Development and Research Center.

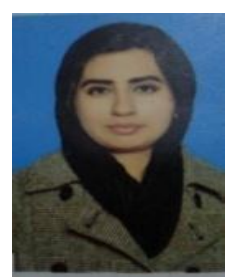

Aalyia Yasmin was born in Fateh Jang Dist. Attock in Pakistan in 1986. She is an MPhil scholar of linguistics and currently teaching in International Islamic University, Islamabad. Her major is English linguistics. She did her BS and MA degrees in English literature and language from International Islamic University, Islamabad, Pakistan in 2009 and 2010, respectively. She has taught in colleges for two years. She has participated and presented a paper titled "Attitudes towards language variation: An analysis of Punjabi speakers' attitudes towards lexical adaptations in Punjabi from English," in the $2^{\text {nd }}$ International Conference on Linguistics, held in Azad Kashmir University, Pakistan. 